\title{
Comparative Reliability of the PEDI, GMFM and TUG Tests for Children with Cerebral Palsy
}

Thomas Besios, MSc, PT ${ }^{1)}$, Aggeloussis Nikolaos ${ }^{1)}$, Gourgoulis Vassilios ${ }^{1)}$, Batsiou Shophia ${ }^{1)}$

1) Department of Physical Education and Sport Science, Dimokritio University of Thrace: Amalias 28, Trikala, 42100, Greece.TEL: +30 2431037706,E-mail:tombesios@yahoo.gr

\begin{abstract}
Purpose] The aim of this research was to determine the reliability of: the Gross Motor Functional Measure (GMFM-88), the Pediatric Evaluation of Disability Index (PEDI) and the Timed Up and Go (TUG) test for children with cerebral palsy. [Subjects] Twenty children with CP took part in the research (7 with tetraplegia, 6 with diplegia and 7 with right hemiplegia). The children's mean age was $4.85 \pm 2.49$ years, their mean height was $1.06 \pm 0.17 \mathrm{~m}$ and their mean body mass $18.58 \pm 7.5 \mathrm{~kg}$. [Methods] All three tests were conducted twice on two separate days, under the same conditions. The intra-class correlation coefficient (ICC), mean RMS difference, standard error of measurement (SEM) and the coefficient of variation (CV) were used to quantify the reliabilities of the tests. [Results] The GMFM, PEDI and TUG tests presented very high reliability scores $(\mathrm{ICC}=0$. 99). [Conclusion] These findings are in accordance with the findings of other studies concerning the reliability of the three tests for children with cerebral palsy or other patient populations. Therefore, it was concluded that all the three tests should be applied in order to reliably estimate the mobility and functional ability of children with cerebral palsy.

Key words: Reliability, GMFM-PEDI-TUG, Cerebral palsy
\end{abstract}

(This article was submitted Aug. 21, 2012, and was accepted Sep. 30, 2012)

\section{INTRODUCTION}

Cerebral palsy $(\mathrm{CP})$ is a neuromuscular disorder that includes a number of symptoms resulting from dysfunction of specific brain areas. These dysfunctions are permanent, they do not evolve and their symptoms lead to motor disorders with or without sensory disturbances ${ }^{1)}$. The exact causes of $\mathrm{CP}$ are not known and they are simply classified as prenatal (during fetal life), perinatal (during labor) and postnatal (after birth) ${ }^{2}$. In an epidemiological study Odding et $\mathrm{al}^{3}{ }^{3)}$ found that the frequency of $\mathrm{CP}$ worldwide is 1 . 0 to 2.3 per 1000 births and involves 1 in 20 premature newborns. Moreover, newborns with birth weights lower than $2.5 \mathrm{~kg}$ have greater incidenceof $\mathrm{CP}$ than full-term newborns. The frequency of CP in America increased from 1.9 to 2.3 per 1000 births between 1960 and 1986, while in Australia, the frequency of $\mathrm{CP}$ was estimated between 2. 0 and 2.5 per1000 births ${ }^{4,5)}$. Mobility and functional ability are critical issues for the quality of life of children with $\mathrm{CP}$. Consequently, a number of tests and evaluation tools are used, in a holistic approach, to assess the mobility and functional ability of children with CP. These tests involve the Gross Motor Function Measure (GMFM), the Paediatric Evaluation of Disability Index (PEDI) and the Timed Up and Go (TUG) Test. The reliability of these tests for children with disabilities has been examined in a number of studies. Russel et al. ${ }^{17)}$ found excellent reliability for the GMFM, using123 children with Down Syndrome over a 6-month period (ICC > 0.90). Ruck et al. ${ }^{6}$ ) examined the reliability of the GMFM, using 19 children with incomplete osteogenesis and 6 independent raters. The results show that GMFM had very high intra-rater and inter-rater reliabilities with ICCs of 0.99 and 0.98 , respectively. Shi et al. ${ }^{7}$ examined the reliability and validity of the GMFM-66 using 171 children with cerebral palsy, ranging in between 3 and 36 months and found very high intra-rater $(\mathrm{ICC}=0.966)$ and interrater $\left(\mathrm{ICC}=0\right.$. 978) reliabilities. Linder et al. ${ }^{8}$ ) studied the reliability of the Gross Motor Function Measure for children and adolescents with traumatic brain injuries. Seventythree patients, aged between 0.8 and 18.9 years, with moderate-to-severe traumatic brain injury were recruited in 12 rehabilitation centers and assessed twice with the Gross Motor Function Measure- 88 over 4 to 6 weeks. The results showed the excellent reliability (ICC $=0.99)$ GMFM-88. Wassenberg et al. ${ }^{9}$ evaluated the reliability of the Dutch version of the Pediatric Evaluation of Disability Inventory (PEDI). Parents of 63 nondisabled and 53 disabled (various diagnoses) children, aged between 7 and 88 months, were interviewed. Although small adaptations had to be made, the psychometric properties of the Dutch PEDI were found to be good $(\mathrm{ICC}<0.90)$. Berg et al. ${ }^{10}$ ) investigated the inter-rater, inter-respondent and intra-rater reliabilities of the Norwegian version of the PEDI. Reliability was investigated in a sample of 30 Norwegian children without disabilities between 1. 0 and 5. 0 years. Interviews with parents were conducted twice by the same occupational therapist, and once by a physiotherapist. All the examined types of reliability were found to be excellent (ICCs between 0. 95 and 0. 99). Erkin et 
al. ${ }^{11)}$ investigated the validity and reliability of the Turkish translation of the original Pediatric Evaluation of Disability Inventory (PEDI). They examined 573 healthy Turkish children (295 males and 278 females; age range: 7 months to 7. 5 years) in two different healthcare centres in Ankara and their results show that the reliability of the Turkish version of the test was excellent (ICC $>0.96$ ).

The reliability of the Timed Up and Go (TUG) test has been well demonstrated in healthy children but few studies have examined children with CP. Williams et al. ${ }^{12)}$ examined the reliability of the TUG test in 176 healthy children (aged 3-9 years) and 41 children with CP (aged 3-9 years) and found that the reliability was excellent (ICC $=0.99$ ). Britt et al. ${ }^{13)}$ also found a good reliability for the TUG test ICC $>0$. 94), among 6 gait performance tests, in individuals with chronic mild to moderate post-stroke hemiparesis. The participants were fifty men and women (mean age $58 \pm 6.4$ years) 6-46 months post-stroke. $\mathrm{Ng}$ and Hui Chan ${ }^{14)}$ examined the reliability of the TUG test and its ability to differentiate between subjects with chronic stroke from healthy elderly subjects. The ICCs of the TUG scores were greater than 0.95 . Jonsdottir and Cattaneo ${ }^{15}$ ) examined 25 subjects, at least 3 months post-stroke and able to walk at least $10 \mathrm{~m}$ with or without a walking aid. ICCs for testretest and inter-rater reliability of total scores were very good (both greater than 0.96). Sue-Mae Gan et al. ${ }^{16)}$ studied the validity and reliability of the Functional Reach Test, the Berg Balance Scale (BBS) and the TUG tests using 30 children with CP, aged from 60 to 142 months. Their results show that all the tests had exceptional test - retest $(\mathrm{ICC}>0$. 95 ) and inter-rater reliabilities (ICC $>0.98)$. From the above it can be concluded that the reliability of the Gross Motor Function Measure (GMFM), the Paediatric Evaluation of Disability Index (PEDI) and the Timed Up and Go (TUG) test for children with CP has not been studied thoroughly. The determination of the reliability of the tests is essential for the accurate and reliable assessment of the mobility and functional ability of children with CP and would help in the design of improved rehabilitation programs.

\section{SUBJECTS AND METHODS}

Twenty children with CP took part in the research (7 with tetraplegia, 6 with diplegia and 7 with right hemiplegia). The children's mean age was $4.85 \pm 2.49$ years, their mean height was $1.06 \pm 0.17 \mathrm{~m}$ and their mean body mass 18 . $58 \pm 7.50 \mathrm{~kg}$. The individuals had been diagnosed by a specialist neurologist and/or pedoneurologist. They had no dysfunctions such as sensibility loss or infection from other illness, they had not received any orthopaedic operation or drug treatment 6 months prior to the research, and they had not participated in any therapeutic programs other than physiotherapy. According to the Gross Motor Function Classification System Level, 9 children were at level I, 7 children were at level II and 4 children were at level IV. The Gross Motor Functional Measure (GMFM-88) was designed to evaluate the change of gross mobility in children with CP. The GMFM is a standardized and validated observational instrument designed to measure changes in gross motor function over time in children with cerebral palsy. Administering the GMFM-88 takes approximately 45-60 minutes for someone familiar with the measure, depending on the skill of the assessor, the ability level of the child and the child's level of cooperation and understanding. The Pediatric Evaluation of Disability Index (PEDI), is a measurement tool for which parents give their answers to questions in a structured interview. PEDI is an instrument for evaluating function in children with disabilities aged 6 months to 7.5 years. The PEDI measures both functional performance and capability in three domains: self-care, mobility, and social function. In Timed Up and Go (TUG) test, the child has to stand up from a chair, walk for 3 meters, turn around and return to sit again on the chair. The score of the test is the time that is required to complete the test. All three tests were performed twice on two consecutive days. During the first measurement (T1), the children were randomly selected for assessment. The second measurement (T2) was performed one day after the first measurement. The tests of the second measurement were performed in the same order and under the same conditions as the first measurement. For statistical analysis of the data the intra-class correlation coefficient (ICC), the square root of the score differences (RMSdif) between the two measurements, the standard error of measurement (SEM), the coefficient of variation $(\mathrm{CV})$ and the limits of agreement (LOA) between the two measurements (T1 and T2) were calculated. Bland-Altman plots were also constructed to show possible trends in the scoring of each test.

Parents had no reservations or anxieties about presenting their children for the measurements because they knew that the research had the purpose of finding the most appropriate test to measure the efficacy of the rehabilitation programs for their children.

\section{RESULTS}

From the results presented in Table 1 it can be seen that all tests showed excellent reliabilities for both their overall scores and their sub-scores. In particular, the ICC coefficients of all the tests were higher than 0.994. The mean RMSdifs between the two measurements were lower than $3 \%$ for the GMFM and the PEDI test, while it was more than 5\% for the TUG test. The standard error of measurement (SEM) was lower than 1 unit for all the tests. Also, the coefficient of variation $(\mathrm{CV})$ was lower than 3\% for the GMFM and the PEDI tests, while it was greater than $5 \%$ for the TUG test. From Figures 1 to 3 it can be seen that there was no significant trend in the reliabilities of the total GMFM score, the total PEDI score and the TUG score. Their limits of agreement (LOA) were $0.5 \pm 1.3,0.1 \pm 2.0$ and $0.2 \pm 2$. 6, respectively.

\section{DISCUSSION}

In the present research the reliabilities of the Gross Motor Functional Measure (GMFM-88), the Pediatric Evaluation of Disability Index (PEDI) and the Timed Up and Go (TUG) test were studied for children with cerebral palsy. The GMFM test showed a very high reliability for the children 


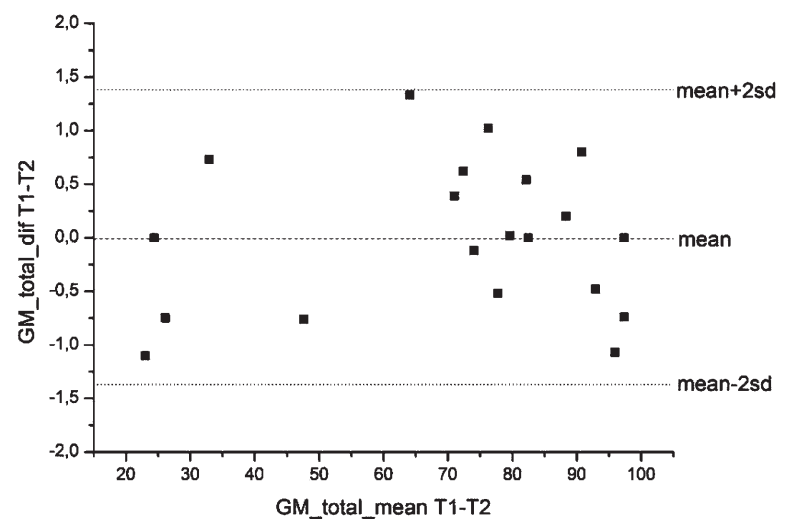

Fig. 1. Bland-Altman plot for the total GMFM score

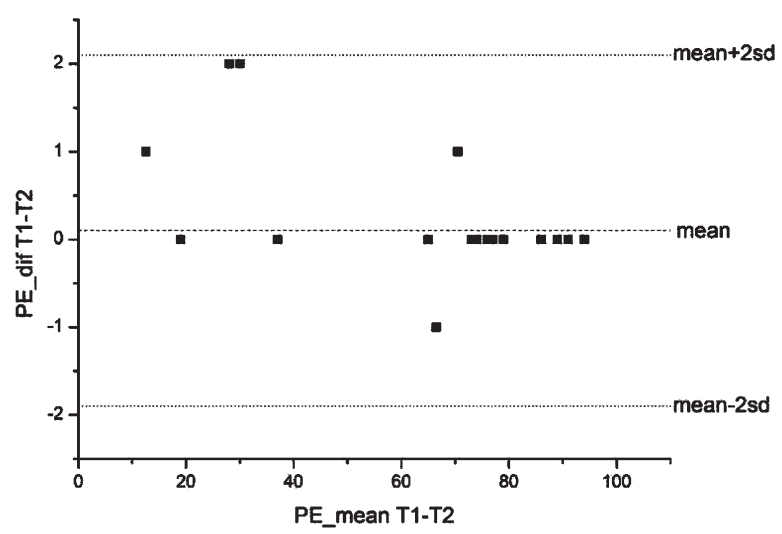

Fig. 2. Bland-Altman plot for the total PEDI score

with cerebral palsy, independent of the gender, age or form of cerebral palsy (tetraplegia, diplegia, hemiplegia). These results agree with findings of similar studies of children with cerebral palsy ${ }^{7}$ and other disorders such as Down Syndrome ${ }^{17)}$ incomplete osteogenesis ${ }^{6)}$ and traumatic brain injury ${ }^{8)}$. The PEDI test results also showed very high reliability. This finding agrees with similar studies of children with various disorders other than $\mathrm{CP}$ or of healthy children $^{9-11)}$. The TUG test results also showed very high reliability, though it was slightly lower than the reliabilities of GMFM-88 and PEDI. Similar studies in the past showed the very high reliability of the TUG test for children with $\mathrm{CP}^{12,16)}$ and stroke patients ${ }^{14,15)}$. On the contrary, KartzLeurer et al. ${ }^{18)}$ found that the reliability of the TUG test for children with traumatic brain injury $(\mathrm{ICC}=0.85)$ was less than the reliability determined in the current study. This difference may be attributable to the different characteristics of the samples in the two studies (traumatic brain injury vs CP children).

From the above it was evident that all three tests are very reliable for the assessment of the mobility and functional ability of children with CP. However, it should be noted that the GMFM took almost 45 minutes to conduct for each child and some children showed a low level of collaboration with

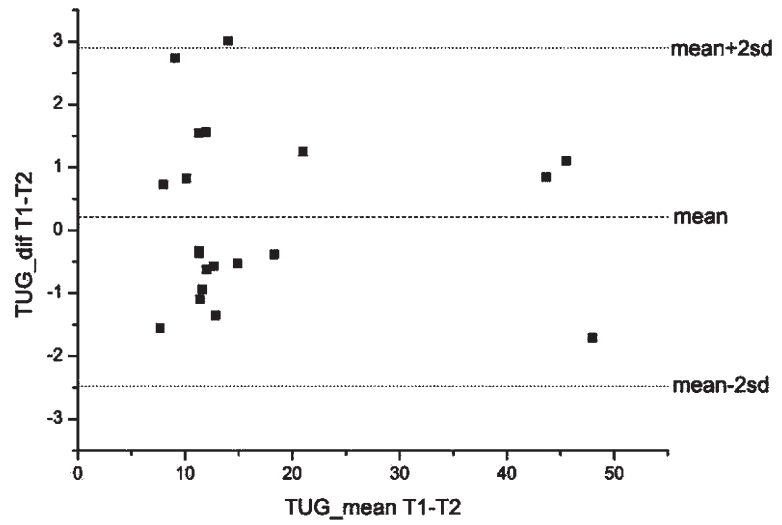

Fig. 3. Bland-Altman plot for the TUG scores

Table 1. Indices of reliability for the three tests

\begin{tabular}{lcccc}
\hline Performances & ICC & $\begin{array}{c}\text { RMSdif }(\%) \\
(\operatorname{mean} \pm \text { SD) }\end{array}$ & SEM & $\begin{array}{c}\text { CV\% } \\
(\operatorname{mean} \pm \text { SD) }\end{array}$ \\
\hline GMFM & $0.999^{*}$ & $0.76 \pm 0,86$ & 0.50 & $0.75 \pm 0.8$ \\
GMFM-A & $0.997^{*}$ & $0.73 \pm 1.10$ & 0.58 & $0.73 \pm 1.1$ \\
GMFM-B & $0.998^{*}$ & $0.67 \pm 1.16$ & 0.60 & $0.68 \pm 1.1$ \\
GMFM-C & $0.999^{*}$ & $2.23 \pm 5,17$ & 0.49 & $2.05 \pm 4.4$ \\
GMFM-D & $0.998^{*}$ & $1.56 \pm 3.62$ & 0.56 & $1.49 \pm 3.3$ \\
GMFM-E & $0.999^{*}$ & $1.75 \pm 2.49$ & 0.60 & $1.17 \pm 2.3$ \\
PEDI & $0.999^{*}$ & $0.98 \pm 1.84$ & 0.72 & $1.00 \pm 1.9$ \\
PEDI-A & $0.998^{*}$ & $1.43 \pm 2.65$ & 0.72 & $1.48 \pm 2.7$ \\
PEDI-B & $0.999^{*}$ & $0.01 \pm 0.02$ & 0.01 & $0.01 \pm 0.0$ \\
TUG & $0.994^{*}$ & $6.19 \pm 4.94$ & 0.97 & $6.35 \pm 5.3$ \\
\hline p $<0.001$ & & & &
\end{tabular}

the examiner in performing this test. Thus, in many cases it may be necessary for the examiner to use various artifices and toys in order to focus the children on performing the various modules of this test. On the other hand, the TUG test took at most only 3 minutes per child. However, some children had some difficulty in finding their way back to the chair and had to be guided verbally by the examiner in order to complete the test. No difficulties were encountered when conducting the PEDI test. In conclusion, the results of the current study suggest that, the Gross Motor Functional Measure, the Pediatric Evaluation of Disability Index and the Timed Up and Go test are very reliable when conducting for children with cerebral palsy, independent of their gender, age and form of cerebral palsy (tetraplegia, diplegia, hemiplegia). It is recommended that all the three tests should be administrated together, in a holistic approach, to assess the mobility and the functional ability of children with cerebral palsy. This is a critical issue since more and more children with $\mathrm{CP}$ are being born worldwide and the utilization of the best strategies for their assessment is becoming more than necessary.

Some limitations of our study need to be considered. First there was no random selection of the sample due to the limited number of children with $\mathrm{CP}$ in relation to the 
general population. Second, some children had executive dysfunction due to mental retardation and this decreased the accuracy of evaluation. Finally the number of children that were studied was small so it is hard to generalize the results.

\section{REFERENCES}

1) Bobath B: Abnormal postural reflex activity caused by brain lesions Rockville, Maryland: Aspen Publication., 1965, pp 15-68.

2) Koman LA, Smith BP, Shilt JS: Cerebral Palsy. Lancet, 2004, 363: 1619-1631. [Medline] [CrossRef]

3) Odding E, Roebroeck ME, Stam HJ: The epidemiology of cerebral palsy: incidence, impairments and risk factors. Disabil Rehabil, 2006, 28 183-191. [Medline] [CrossRef]

4) Lin JP: The cerebral palsies: a physiological approach. J Neurol Neurosurg Psychiatry, 2003, 74: i23-29. [Medline] [CrossRef]

5) Paneth N, Hong T, Korzeniewski S: The descriptive epidemiology of cerebral palsy. Clin Perinatol, 2006, 33: 251-267. [Medline] [CrossRef]

6) Ruck-Gibis J, Plotkin H, Hanley J, et al.: Reliability of the gross moto function measure for children with osteogenesis imperfecta. Pediatr Phys Ther, 2001, 13: 10-17. [Medline] [CrossRef]

7) WeiS, Su-JuanW, Yuan-GuiL, et al.: Reliability and validity of the GMFM -66 in $0-3$ years old children with cerebral paralysis. Am J Phys Med Rehabil, 2006, 85: 141-147. [Medline] [CrossRef]

8) Linder ML, Othmer V, Walther M, et al.: Validation of the gross motor function measure for use in children and adolescents with traumatic brain injuries. Pediatrics, 2007, 120: e880-e886. [CrossRef]

9) Wassenberg-Severijen JE, Custers JW, Hox JJ, et al.: Reliability of the dutch pediatric evaluation of disability inventory. Clin Rehabil, 2003, 17: 457-462. [Medline] [CrossRef]

10) Berg M, Jahnsen R, Froslie KF, et al.: Reliability of the pediatric evaluation of disability inventory. Phys Occup Ther Pediatr, 2004, 24: 61-77. [Medline] [CrossRef]

11) Erkin G, Elhan AH, Aybay C, et al.: Validity and reliability of the Turkish translation of the Pediatric Evaluation of Disability Inventory (PEDI). Disabil Rehabil, 2007, 29: 1271-1279. [Medline] [CrossRef]

12) Williams EN, Caroll S, Reddihourh DS, et al.: Investigation of the timed up and go test in children. Dev Med Child Neurol, 2005, 47: 518-524. [Medline] [CrossRef]

13) Flansbjer UB, Holmback A, Downham D, et al.: Reliability of gait performance tests in men and women with hemiparesis after stroke. J Rehabil Med, 2005, 37: 75-82. [Medline] [CrossRef]

14) Ng SS, Hui Chan CW: The timed up and go test: its reliability and association with lower-limb impairments and locomotor capacities in people with chronic stroke. Arch Phys Med Rehabil, 2005, 86: 1641-1647. [Medline] [CrossRef]

15) Jonsdottir J, Cattaneo D: Reliability and validity of the dynamic gait index in persons with chronic stroke. Arch Phys Med Rehabil, 2007, 88: 1410-1415. [Medline] [CrossRef]

16) Gan SM, Tung LC, Tang YH, et al.: Psychometric properties of functional balance assessment in children with cerebral paralysis. Neurorehabil Neural Repair, 2008, 22: 745-753. [Medline] [CrossRef]

17) Russell D, Palisano R, Walter $S$, et al.: Evaluating motor fuction in children with down sydrome: validity of the GMFM. Dev Med Child Neurol, 1998, 40: 693-701. [Medline] [CrossRef]

18) Katz-LeurerM, RotemH, LewitusH, et al.: Functional balance tests for children with traumatic brain injury within-session reliability. Pediatr Phys Ther, 2008, 20: 254-258. [Medline] [CrossRef] 